\title{
A PERCEPÇÃO DOS ALUNOS DO CURSO DE FISIOTERAPIA EM RELAÇÃO À DISCIPLINA DE ATIVIDADE PRÁTICA ASSISTIDA DA UNIVERSIDADE DE UBERABA, MG
}

\section{THE PERCEPTION OF PHYSIOTHERAPY COURSE STUDENTS REGARDING SUPERVISED PRACTICE ACTIVITY DISCIPLINE AT THE UNIVERSITY OF UBERABA}

\author{
Cristina Ruiz ${ }^{1}$ \\ Silvana Ruiz Takao ${ }^{1}$ \\ Luciane Fernanda Rodrigues Martinho Fernandes ${ }^{2}$
}

\begin{abstract}
Resumo: Segundo as diretrizes curriculares de 2002, as atividades práticas específicas da fisioterapia deverão ser desenvolvidas gradualmente desde o início do curso de graduação. 0 objetivo deste estudo foi verificar a percepção dos alunos do curso de fisioterapia em relação à disciplina de atividade prática assistida da Universidade de Uberaba, MG. Tratou-se de um estudo descritivo com uma abordagem qualitativa e quantitativa. A população pesquisada foi constituída de 91 alunos do curso de fisioterapia, matriculados nos estágios ambulatorial I, hospitalar, ambulatorial II e saúde coletiva que realizaram a atividade prática assistida de I a VI, desde o primeiro ano do curso de fisioterapia na Clínica de Fisioterapia da Universidade de Uberaba em 2008. O instrumento de análise foi um questionário abordando diversas questões relacionadas à experiência do aluno, e a sua percepção sobre a atividade prática assistida no curso de fisioterapia desde o primeiro semestre do curso. Os resultados foram analisados qualitativamente e quantitativamente. Os dados quantitativos foram organizados em planilha Excel, submetidos à análise de freqüência simples, permitindo caracterizar a população do estudo. Os dados qualitativos foram analisados com base nas respostas descritivas obtidas. Para $76 \%$ dos entrevistados, a disciplina de atividade prática assistida foi extremamente importante para a atuação na prática clínica e para $94,5 \%$ dos alunos a sua realização contribuiu para a segurança no estágio curricular. Concluiu-se que a implantação da atividade prática assistida desde o início do curso de fisioterapia foi importante para a atuação na prática clínica e que a sua realização contribuiu para a segurança do aluno no estágio curricular.
\end{abstract}

Palavras-chave: Aprendizagem. Currículo. Ensino. Estágio Supervisionado. Fisioterapia.

\begin{abstract}
According to 2002 Curricular Directives, the specific activity of physiotherapy should be developed gradually from the beginning of undergraduate course. The aim of this paper was to verify the perception of physiotherapy course students regarding supervised practical activity discipline at the University of Uberaba, M.G. It is a descriptive study with both a qualitative and a quantitative approach. The population researched was 91 physiotherapy students in ambulatory I, hospital, ambulatory II and collective health who applied to assisted practice activity from I to VI from the first year of physiotherapy course in the Clinic of Physiotherapy at the University of Uberaba in 2008. The instrument of analysis was a questionnaire with several questions about the relationship of students experience and their perceptions about supervised practice activity in the physiotherapy course from the first semester of the course. The results were analyzed qualitatively and quantitatively. Quantitative data was organized by Excel spreadsheets and submitted to simple frequency analysis to characterize the studied population. Qualitative analysis had as object descriptive answers obtained. For $76 \%$ of the participants, the discipline is extremely important for later clinical practice and for $94.5 \%$ of the students, it contributed to a confident practice during preservice training. We concluded that the implantation of the discipline from the

\footnotetext{
${ }^{1}$ Alunas do Curso de Especialização em Docência na Educação Superior da Universidade Federal do Triângulo Mineiro, crr.ruiz@terra.com.br e msgt@terra.com.br.

${ }^{2}$ Professora da Universidade Federal do Triângulo Mineiro, Ifrmf@terra.com.br.
} 
beginning of the physiotherapy course was important to clinical practice and that it contributed to a confident practice during preservice training.

Keywords: learning. Curriculum. Teaching. Supervised practice.Physiotherapy.

\section{Introdução}

O projeto pedagógico deve "expressar a reflexão e o trabalho realizado em conjunto por todos os profissionais da escola, no sentido de atender às diretrizes do sistema nacional de Educação, bem como às necessidades locais e específicas da clientela da escola"; ele é "a concretização da identidade da escola e do oferecimento de garantias para um ensino de qualidade" (ANDRÉ, 2001 apud BAFFI, 2002). A partir da adoção de um modelo inclusivo centrado nos princípios da cidadania, autonomia e ética, o projeto pedagógico, norteado pela flexibilização curricular para mudanças contextuais e pela interdisciplinaridade, visa oferecer ao aluno a possibilidade do desenvolvimento da autonomia intelectual, de uma visão crítica, reflexiva e humanística (UNIUBE, 2003).

É dentro desta perspectiva que a Universidade de Uberaba, por meio da aliança do Projeto Pedagógico com os recursos humanos e materiais disponíveis, e respondendo ao desafio de seu papel transformador, implantou o curso de Fisioterapia. E desta forma vem contribuindo para a concepção de profissionais com sólida formação técnicocientífica, dotada de postura ética, consciência crítica, humanista, participativa e comprometida com os interesses coletivos da população (UNIUBE, 2003).

A elaboração do projeto pedagógico do curso de fisioterapia da Universidade de Uberaba considerou o que preceitua o Decreto-Lei 938, de 13/10/1. 969, a Lei 7.439/85, o parecer 622/82, do Conselho Federal de Educação, a Lei de Diretrizes e Bases da Educação Nacional, LDB - n. ${ }^{\circ} 9.394$ de 20/12/1. 996 e as Diretrizes Curriculares Nacionais do Curso de Graduação de Fisioterapia, Resolução nº CNE/CES 4, de 19 de fevereiro de 2002 (UNIUBE, 2003).

A carga horária total do curso de fisioterapia da Universidade de Uberaba perfez 3603 horas/aulas. O desenvolvimento de atividades práticas durante o curso teve dois principais momentos: as aulas de atividade prática assistida (180 horas/aula), e o estágio curricular (873 horas/aula). O processo de aprendizagem no campo de estágio ou das atividades práticas durante o curso revestiu-se de grande importância no processo de formação dos alunos, possibilitando-Ihes experiências enriquecedoras, adquiridas desde a observação até a prática, desde o concreto até a abstração e a transformação (ABREU; MASETTO, 1990). 
Por meio das Diretrizes Curriculares Nacionais do Curso de Graduação de Fisioterapia, Resolução n CNE/CES 4, de 19 de fevereiro de 2002, pelo art.13 a estrutura do Curso de Graduação em Fisioterapia deveria assegurar que: "parágrafo I - as atividades práticas específicas da Fisioterapia deverão ser desenvolvidas gradualmente desde o início do Curso de Graduação em Fisioterapia, devendo possuir complexidade crescente, desde a observação até a prática assistida; parágrafo II- estas atividades práticas, que antecedem ao estágio curricular, deverão ser realizadas na instituições de ensino superior ou em instituições conveniadas e sob a responsabilidade de docente fisioterapeuta" (MINISTÉRIO DA EDUCAÇÃO, 2002).

O aluno deveria ser criativo e capaz de atualização constante na busca de novos conhecimentos. Tomando como base os conhecimentos adquiridos nas aulas teóricas ministradas, foram desenvolvidos conceitos, atitudes, postura do profissional, habilidades teóricas e práticas, buscando sempre incentivar a participação e o desenvolvimento da criatividade do aluno e a sua capacidade de correlacionar a teoria à prática (UNIUBE, 2003).

O professor é o sujeito que tem a função de educador, a qual incorpora e ultrapassa as dimensões técnicas de seu trabalho, e no decorrer dos anos, adquire força educativa quando se torna instrumento capaz de auxiliar o aluno a atuar concretamente na sociedade de modo crítico e transformador, unindo a teoria à prática (KULCSAR, 2001). Ohl (1995) apud Matheus et al. (1996) relata que a presença do professor junto ao aluno é de extrema importância para que o mestre possa orientá-lo, direcionando-o em seu desenvolvimento, porém ressalta que essa presença necessita ser definida, pois é também o primeiro modelo profissional com que o aluno tem contato e, portanto, este pode espelhar-se nas atitudes dos docentes, acreditando serem estas as ideais.

O Estado de Minas Gerais tem 64 Instituições Educacionais com o curso de Fisioterapia aprovados pelo Ministério da Educação no ano de 2008, sendo que 42 delas não apresentam a disciplina de atividade prática na grade curricular (MINISTÉRIO DA EDUCAÇÃO, 2008).

Este estudo teve como objetivo verificar a percepção dos alunos do curso de fisioterapia em relação à disciplina de atividade prática assistida da Universidade de Uberaba, MG.

\section{Material e Método}

A atividade prática assistida foi instituída na Universidade de Uberaba a partir do ano de 2003, e subdivide-se em atividades práticas I a VI, com carga horária de cada unidade 
temática de 30 horas/aulas de vivências práticas, realizadas na Clínica da Universidade de Uberaba, unidade básica de saúde e instituições conveniadas, perfazendo um total de 180 horas/aulas (UNIUBE, 2003).

A disciplina de atividade prática assistida I, inserida no $1^{\circ}$ período do curso, correspondeu à observação dos atendimentos em todas as áreas de estágio em fisioterapia (UNIUBE, 2003).

A disciplina de atividade prática assistida II, inserida no $2^{\circ}$ período do curso, corresponde à observação dos atendimentos realizados em todas as áreas de estágio em fisioterapia, e realização de atividades práticas com apresentação de relatórios relacionados à disciplina teórico-prática de avaliação cinesiológica funcional e cinesiologia de membros superiores e membros inferiores (UNIUBE, 2003).

A disciplina de atividade prática assistida III está inserida no $3^{\circ}$ período do curso, correspondendo à observação dos atendimentos do estágio curricular de Fisioterapia e desenvolvimento de atividades práticas relacionadas à disciplina teórico-prática de bases, métodos e técnicas de avaliação (UNIUBE, 2003).

A disciplina de atividade prática assistida IV, inserida no curso correspondeu à observação, aplicada a todas as áreas de estágio em fisioterapia e desenvolvimento de atividades práticas relacionadas às disciplinas teóricopráticas de recursos terapêuticos (eletrofototermoterápicos, manuais e cinesioterapêuticos) (UNIUBE, 2003).

A disciplina de atividade prática assistida $\mathrm{V}$, correspondeu ao início das atividades de atendimento do aluno, já que iniciou o estudo das disciplinas teórico-práticas de conteúdos aplicados. Estes conteúdos são de Fisioterapia Aplicada à Ortopedia, Reumatologia e Geriatria (UNIUBE, 2003).

A disciplina de atividade prática assistida VI, objetivou proporcionar ao futuro Fisioterapeuta conhecimento sobre as áreas de atuação profissional, além de possibilitar que o aluno vivenciasse a rotina do atendimento fisioterapêutico em ambiente hospitalar (UNIUBE, 2003).

Tratou-se de um estudo descritivo com uma abordagem qualitativa e quantitativa. $\mathrm{O}$ método qualitativo não se preocupou com representatividade numérica, mas sim com o aprofundamento da compreensão de um grupo social, de uma organização, entre outros elementos. Minayo (1993) salienta que as abordagens qualitativas são aquelas capazes de incorporar a questão do significado e da intencionalidade. Já a pesquisa descritiva teve como objetivo conhecer e interpretar a realidade sem nela interferir para modificá-la. 
Neste tipo de investigação residiu o interesse em descobrir e observar fenômenos, procurando descrevê-los, classificá-los e interpretá-los.

A população pesquisada foi constituída de alunos dos estágios ambulatorial I, hospitalar, ambulatorial II e saúde coletiva que realizaram a atividade prática assistida de I a VI, desde o primeiro ano do curso de fisioterapia na Clínica de Fisioterapia da Universidade de Uberaba em 2008. A população estudada foi constituída de 91 alunos, de ambos os sexos, todos maiores de 18 anos.

O instrumento utilizado foi um questionário aplicado por três profissionais Fisioterapeutas e que atuam na instituição de ensino superior. Previamente foi realizado um pré-teste a fim de verificar a clareza, objetividade e ordem das perguntas. $\mathrm{O}$ pré-teste foi aplicado em 15 alunos que realizaram a atividade prática assistida desde o início do curso de fisioterapia e as respostas não foram utilizadas na análise final. Após a aplicação do pré-teste, houve a necessidade correções e adaptações na estruturação do questionário.

O questionário aplicado constou de questões abertas e fechadas, abordando qual a percepção do aluno em relação à atividade prática assistida (APA) desde o primeiro ano do curso letivo. Tratou-se de um questionário estruturado, abordando os itens: importância da implantação da atividade prática assistida; a segurança para atuar no estágio curricular; a satisfação em relação à carga horária, a ordem de distribuição das disciplinas alvo; a necessidade de outra área de atuação no estágio; condutas que contribuíram para o aprendizado; a estrutura de funcionamento e o local; as características mais marcantes do professor; fatores que estimularam; favoreceram e prejudicaram o aprendizado; o papel do professor para a função de supervisor; avaliação do aspecto contribuição para a formação profissional e sugestões para a melhoria da atividade prática assistida.

Dos 124 alunos matriculados no curso de Fisioterapia, 15 participaram do pré-teste, 4 alunos não realizaram a disciplina de atividade prática assistida por motivos curriculares, 2 alunos recusaram-se a responder o questionário e 12 alunos não foram entrevistados, pois não foram localizados durante o período de coleta dos dados.

O questionário foi organizado em questões que correspondem às partes $A, B, C$ e D.

A parte $A$ foi composta por 10 questões que são numeradas de 1 a 10 . Na questão 1 foi questionada a relação ao grau de importância da implantação da APA, segundo os critérios: não é importante, importante, muito importante e extremamente importante. As questões de número 2 a 9 com as respostas: sim ou não. Na questão 10, foi solicitada a 
característica marcante do professor que atua na APA. Na parte B as questões de 11 a 14 foram enumeradas por ordem crescente e prioridade, segundo os critérios: indiferente, sem importância, importante, muito importante e extremamente importante. Na parte C a questão 15 consta de uma escala de 0 a 5 quanto ao desenvolvimento da sua segurança no atendimento aos pacientes do estágio curricular. A parte $D$ contém questões abertas de número 16 e 17.

Foi exposta aos alunos a intenção da pesquisa e a solicitação para o preenchimento do questionário, o qual foi preenchido, de forma manual na sala de aula. Com tempo de 10 minutos para esclarecimento da pesquisa e 30 minutos para o preenchimento do questionário. Aos participantes do estudo foram assegurados o anonimato e a privacidade como também o direito de não responderem ao questionário, se assim o desejassem. O trabalho foi aprovado pelo Comitê de Ética em Pesquisa, envolvendo seres humanos da Universidade Federal do Triângulo Mineiro, protocolo $\mathrm{n}^{\circ}$ 1117.

A análise dos dados foi realizada, segundo os critérios das abordagens com base no referencial teórico da área educacional e de fisioterapia. Os dados quantitativos foram organizados em planilha Excel, submetidos à análise de freqüência simples, permitindo caracterizar a população do estudo. Os dados qualitativos foram analisados mediante as respostas descritivas, no sentido de resgatar dados que pudessem elucidar o cotidiano do aprendizado dos alunos desde o primeiro ano do curso.

\section{Resultados}

Após análise dos 91 questionários, as respostas objetivas e os comentários ou justificativas dos sujeitos foram organizadas, seguindo a ordem das questões em parte: $A$, B, C e D.

Na Parte $A$, a primeira questão se referiu à implantação da atividade prática assistida desde o início do curso de fisioterapia, nenhum entrevistado considerou que não fosse importante, $12 \%$ (11 entrevistados) dos sujeitos responderam que foram importantes $12 \%$ (11entrevistados) dos sujeitos responderam que foi muito importante e $76 \%$ (69 entrevistados) consideraram que foi extremamente importante com a justificativa de que: "passou a ter uma vivência com a prática desde o início do curso" (31 entrevistados), "conhecer o curso e sobre a fisioterapia" (20 entrevistados),"melhorou a integração entre paciente e colegas" (12 entrevistados), "percepção da aprendizagem" (4 
entrevistados) e "conheceu o funcionamento da clínica"(4 entrevistados),conforme visualizado na figura 1.

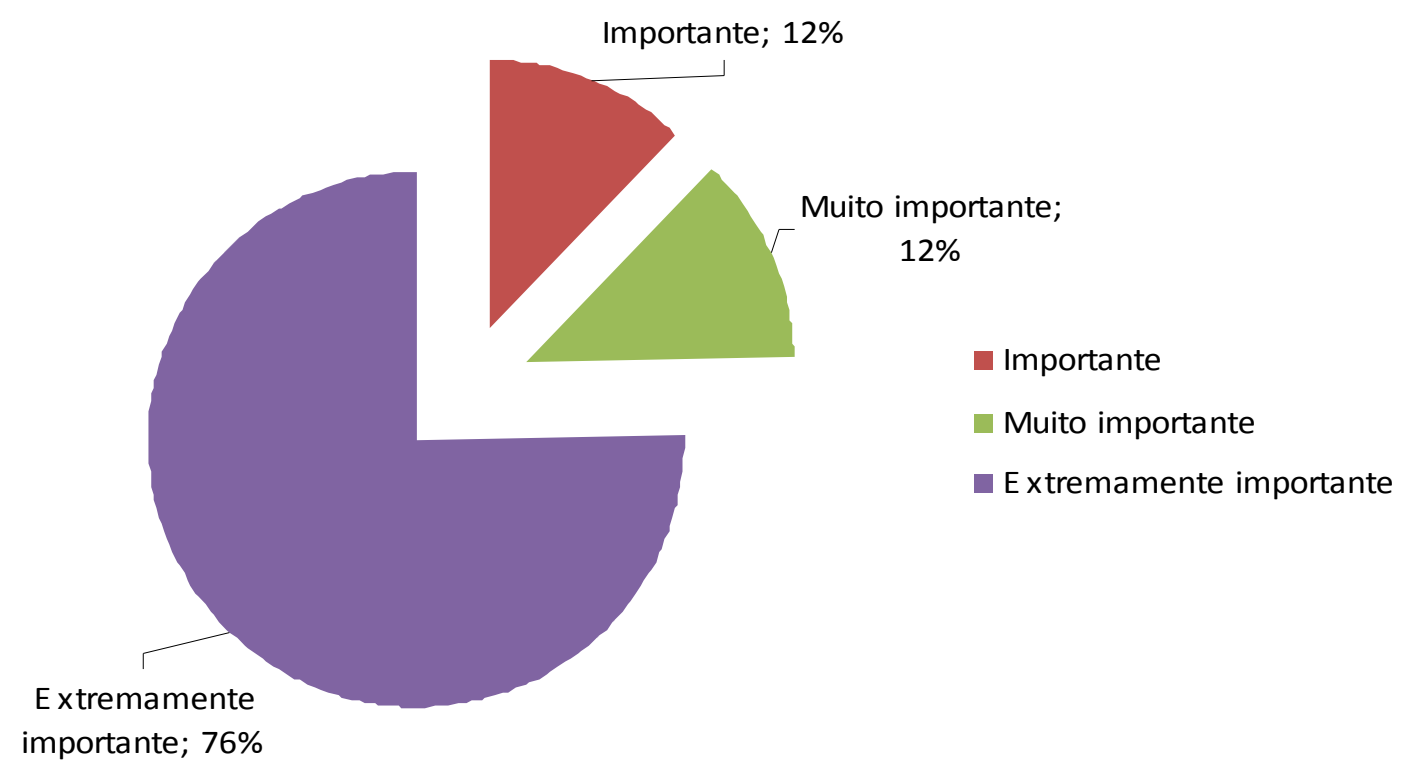

Figura 1. Apresentação gráfica da importância da implantação da atividade prática assistida desde o início do curso.

$\mathrm{Na}$ questão dois, 94,5\% (86 entrevistados) afirmaram que a atividade prática assistida contribuiu para a segurança durante o estágio curricular, colocando que "diminuiu a insegurança frente ao primeiro contato com os pacientes e as patologias" (28 entrevistados), "por já conhecermos o funcionamento da clínica" (11 entrevistados) e "experiência prática adquirida durante a observação" (11 entrevistados).

$\mathrm{Na}$ questão 3, em relação à carga horária apropriada, 52\% (47 entrevistados) disseram sim, relatando "que a carga horária foi bem distribuída" (30 entrevistados), e 48\% (44 entrevistados) responderam "poderíamos ter uma carga horária maior" (35 entrevistados).

Ao serem questionados sobre a ordem de distribuição das atividades prática assistida de I a VI sobre a integração com as disciplinas alvo, 59\% (54 entrevistados) responderam sim, tendo como justificativa que "interagiu a prática com a teoria" (38 entrevistados) e 41\% (37 entrevistados) responderam não "as aulas teóricas não bateram com a vivência prática" (29 entrevistados). 
$\mathrm{Na}$ questão 5, quanto à inclusão de outro estágio, 78\% (71 entrevistados) responderam sim. Dentre os estágios que julgaram necessários, 31 sujeito responderam que sim em dermatofuncional, 7 sujeitos em ginecologia, 6 sujeitos em estética, 4 sujeitos em saúde coletiva, 4 sujeitos em equoterapia e 3 sujeitos em hidroterapia.

Ao serem questionados, se o número de pacientes observados foi adequado para o seu aprendizado, 50,5\% (46 entrevistados) dos sujeitos responderam não, relatando que "poderiam ter tido mais pacientes" (16 entrevistados), "às vezes era o mesmo paciente e somente um por semana (6 entrevistados), " não acompanhei todas as patologias" (6 entrevistados) e 49,5\% (45 entrevistados) responderam sim, com argumentos de que "o número de pacientes foi suficientes" (17 entrevistados), "os pacientes observados sempre eram diferentes a cada semana" (10 entrevistados), "pelo menos as patologias mais freqüentes tivemos uma base" (2 entrevistados).

Em relação à questão 7 , se o número de pacientes observados durante as atividades práticas assistidas foi adequado para a sua atuação no estágio curricular $53 \%$ (48 entrevistados) disseram não, com justificativas de que "o número de pacientes poderia ser maior" (19 entrevistados), "não acompanhei pacientes em todas as áreas de atuação" (9 entrevistados).

Na questão 8, quanto aos recursos didáticos, equipamentos e corpo docente, $63 \%$ (57 entrevistados) disseram sim, justificando que "a estrutura fornecida foi suficiente" (31 entrevistados) e 37\% (34 entrevistados) disseram não, afirmando que "os equipamentos são insuficientes" (16 entrevistados), "faltou recursos didáticos" (9 entrevistados).

A questão 9 foi em relação ao local onde a atividade prática assistida é realizada, 91\% (83 entrevistados) afirmaram que "o local foi adequado" (38 entrevistados), "influenciou na postura profissional" (3 entrevistados).

Os resultados das respostas às questões 2 a 9 podem ser visualizadas na tabela 1 .

Tabela 1. Questões de número 2 a 9 da Parte $A$

\begin{tabular}{lccc}
\hline QUESTÕES & Sim & Não \\
& $(\%)$ & $(\%)$ \\
\hline $\begin{array}{l}\text { 2. Você considera que a realização da atividade prática } \\
\text { assistida contribuiu para sua segurança durante o estágio } \\
\text { curricular? }\end{array}$ & $\mathbf{8 6}$ & $\mathbf{5}$ \\
$\begin{array}{l}\text { 3. Você julga que a carga horária de cada atividade prática } \\
\text { assistida foi apropriada para seu aprendizado? }\end{array}$ & $\mathbf{4 7}$ & $\mathbf{4 4}$ \\
& $(52 \%)$ & $(48 \%)$
\end{tabular}


4. Você acredita que a ordem de distribuição das atividades prática assistida de I a VI teve uma integração com as disciplinas alvo?

$(59 \%) \quad(41 \%)$

5. Você acrescentaria da atividade prática assistida em outra área de estágio que julgue necessário?

7120

$(78 \%) \quad(22 \%)$

$45 \quad 46$

$(49,5 \%) \quad(50,5 \%)$

$43 \quad 48$

$(47 \%) \quad(53 \%)$

57

34

$(63 \%) \quad(37 \%)$

$83 \quad 8$

$(91 \%) \quad(9 \%)$

Ao serem questionados quanto à característica mais marcante de um professor para atuar na atividade prática assistida, 38,4\% (35 entrevistados) responderam que experiente, 26,4\% (24 entrevistado) disseram que o professor deveria ser atencioso, $15,4 \%$ (14 entrevistados) responderam que colaborador, 5,5\% (5 entrevistados) disseram que deveria ser exigente, 4,4\% (4 entrevistados) responderam crítico, 4,4\% (4 entrevistados) responderam amigo, e outras características 5,5\% (5 entrevistados), tais como, tranqüilo, dinâmico, dedicado, disponível e humano em figura 2.

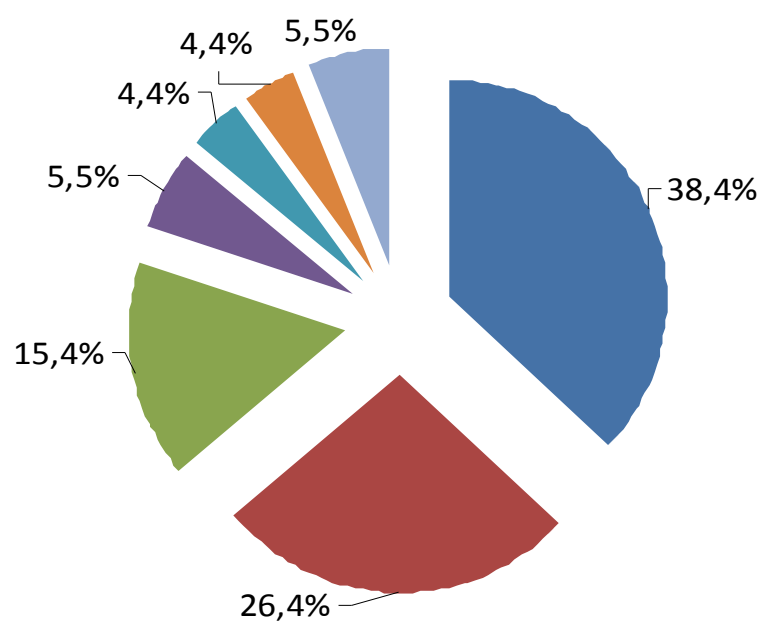

Experiente
Atencioso
Colaborador
Exigente
Crítico
Amigo
Outro

Figura 2. Apresentação gráfica das características mais marcantes de um professor para atuar na atividade prática assistida. 
Na Parte B, a questão 11 se referiu aos fatores que estimularam o aluno durante a realização da atividade prática assistida. Os alunos registraram que a integração do conteúdo teórico vem sendo o principal fator estimulante para a realização da atividade prática assistida. Em seguida a vontade de executar o conteúdo aprendido.

Ao serem questionados sobre os fatores que lhes favoreceram o aprendizado na atividade prática assistida, os alunos responderam em ordem de importância que, em primeiro lugar, veio a discussão dos casos clínicos com o supervisor, em segundo a observação do atendimento, em terceiro a exposição do caso clínico pelo aluno estagiário e em quarto a realização dos relatórios.

Quanto aos fatores que Ihes prejudicaram o aprendizado, os alunos afirmaram que o aluno desinteressado estaria em primeiro lugar, vindo em seguida o aluno sem assiduidade, o aluno que não cumpriu a carga horária e o aluno que não realizou relatórios.

Em relação ao papel do professor como facilitador do aprendizado os alunos caracterizaram por ordem de significância: o professor que criou condições para que o aluno adquirisse um senso crítico, sendo mais reflexivo em suas atitudes, o professor que fosse incentivador do aluno na busca e aperfeiçoamento do conhecimento científico, o que daria apoio ao aluno que necessitou para que se sentisse confiante e o que estimulasse o aluno no alcance dos seus objetivos na atividade prática assistida.

Na Parte C, em relação à questão 15, ao solicitarmos que o sujeito atribuísse uma nota de zero a cinco quanto a sua segurança para atuar no atendimento aos pacientes do estágio curricular, nenhum entrevistado atribuiu zero, $1 \%$ ( 1 entrevistado) pontuou em 1 , $3 \%$ (3 entrevistados) pontuaram em 2, 17,6\% (16 entrevistados) deram nota 3, 30\% ( 27 entrevistados) deram nota 4 e 48,4\% (44 entrevistados) deram nota 5 . Obtivemos uma média de 4,2, sendo que a menor nota foi 1 (em apenas 1 entrevistado), e a maior nota 5 (em 44 entrevistados).

Na parte $D$, na questão de número 16, ao serem questionados sobre qual o papel da atividade prática assistida para a sua formação. Obtive como resposta: "nos inteirar quanto antes do curso sempre relacionando a teoria com a prática" (50 entrevistados), "proporcionou uma maior segurança e aplicação do conhecimento adquirido foi extremamente importante para a formação profissional" (38 entrevistados).

$\mathrm{Na}$ questão de número 17, ao solicitarmos as contribuições para melhorar a atividade prática assistida ao longo dos anos. Obtivemos como sugestões: "que se 
ampliasse a área de atuação em dermato funcional, desportiva, hidroterapia e equoterapia” (24 entrevistados), "houvesse número maior de discussão de casos clínicos" (20 entrevistados), "que se aumentasse a carga horária" (20 entrevistados), "comprasse de equipamentos novos" (16 entrevistados), "melhorasse o espaço interno" (4 entrevistados), "houvesse uma interação dos alunos do estágio curricular com os alunos da atividade prática assistida" (5 entrevistados) e "aumentasse o número de professores" (3 entrevistados).

\section{Discussão}

Após analise dos dados, a partir dos depoimentos dos alunos, pude observar que, na visão do aluno, a implantação da atividade prática assistida, desde o início do curso de fisioterapia, foi extremamente importante para a sua atuação na prática clínica, ao início dos estágios curriculares. Dentre os 91 acadêmicos entrevistados, 29 disseram que passaram a ter uma vivência com a prática desde o início do curso, com a implantação da atividade prática assistida, e 20 entrevistados disseram que essa atividade foi importante para conhecerem o curso e a profissão Fisioterapia. Esta atividade foi um procedimento didático-pedagógico que propiciou ao estudante participação em situações reais de vida e trabalho do seu meio social (RODRIGUES, 1995).

Abreu e Masseto (1990) relataram que o universo de conhecimentos, as experiências vividas, as vivências e as situações que permitem aos alunos formular problemas e questões que, de alguma forma, chamam a sua atenção, permite que os mesmos possam contextualizar o contato experimental com problemas práticos de natureza social, ético e profissional. Esse processo de aprendizagem possibilita ao aluno ter responsabilidades e o ajuda a transferir o conhecimento adquirido na universidade para situações de vida real. Ressalta-se então que toda atividade prática do acadêmico durante a graduação, é extremamente valiosa, incluindo aqui a atividade prática assistida, para que o mesmo aprimore suas habilidades para o mercado profissional.

A realização da atividade prática assistida contribuiu para a segurança do aluno no estágio curricular apontada por $94,5 \%$ dos entrevistados. Dentre os 91 acadêmicos entrevistados, 26 relataram que esta atividade diminuiu a insegurança frente ao primeiro contato com os pacientes e suas patologias, ou seja, se o primeiro contato com os pacientes fosse feito apenas no estágio curricular dos últimos períodos do curso de graduação, a insegurança para atendê-los seria bem maior. Segundo Friedlander (1994), 
o contato do aluno com o paciente pode tornar-se estressante, quando associado ao desconhecido, a insegurança e a condição de não poder errar, resultando em sérios conflitos que dificultam a aprendizagem. Com isso podemos concluir que a disciplina Atividade Prática Assistida proporcionou-lhes segurança e facilitou-lhes o conhecimento do campo de atuação.

A carga horária deste componente curricular foi considerada apropriada por $47 \%$ dos entrevistados, 29 deles alegaram que a carga horária foi bem distribuída, sendo a mesma composta de 180 horas, estando de acordo com o proposto nas Diretrizes Curriculares para os Cursos de Graduação em Fisioterapia pela Resolução CNE/ CES n.4 1902/2002 (MINISTÉRIO DA EDUCAÇÃO, 2002).

Verificou-se que 54 entrevistados consideraram adequada a ordem de distribuição das atividades práticas assistidas, as quais são numeradas de I a VI, e a integração com as disciplinas alvo do curso, porém 37 deles consideraram que a organização das atividades práticas assistidas não está adequada, o que nos leva a concluir que existam ainda lacunas a serem analisadas para que haja uma maior integração entre as disciplinas e assim um maior aproveitamento pelos acadêmicos.

Quanto à inclusão de outras áreas de estágio para acompanhamento na atividade prática assistida, 71 entrevistados apontaram que gostariam de ter acompanhado outros segmentos da Fisioterapia antes dos estágios curriculares. Dentre as áreas que julgaram necessárias na atividade prática assistida estão: Fisioterapia Dermatológica Funcional, Fisioterapia em Ginecologia e Obstetrícia, Fisioterapia em Saúde Coletiva, Equoterapia e Hidroterapia. Estas informações estão relacionadas com as necessidades que os alunos têm vivenciado para a sua formação profissional e podem sugerir que novos projetos pedagógicos sejam implantados no curso de fisioterapia para melhorar o aprendizado do acadêmico, bem como, para prepará-lo mais especificamente para atuar no mercado de trabalho.

Ao serem questionados se o número de pacientes observados na atividade prática assistida foi adequado para o seu aprendizado, 16 entrevistados responderam não e relataram que poderiam ter acompanhado mais pacientes, 6 acadêmicos responderam que em algumas aulas acompanhavam o mesmo paciente e essa situação foi ruim, visto que havia apenas uma aula por semana, outros 6 acadêmicos responderam que não acompanharam todas as patologias englobadas pelas áreas da Fisioterapia, no entanto 45 entrevistados responderam que o número de pacientes observados foi satisfatório. 
Vários responderam que o número de pacientes foi suficiente (14 entrevistados), que os pacientes observados foram sempre diferentes a cada semana (10 entrevistados), e que pelo menos as patologias mais freqüentes de cada área da Fisioterapia foram vistas na prática assistida (2 entrevistados). Sugere-se diante desses números, que os alunos sentiram a necessidade de observar um número maior de pacientes e para que isso se concretizasse precisaria haver uma mudança na carga horária do componente curricular Atividade Prática Assistida e uma alteração na estrutura do projeto pedagógico do curso, o qual está de acordo com as diretrizes curriculares dos cursos de Fisioterapia.

As atividades práticas são realizadas uma vez por semana com observação do atendimento de um paciente em diferentes áreas de atuação fisioterapêutica. Na clínica escola os alunos da atividade prática assistida acompanham e podem observar os alunos do estágio curricular, nos atendimentos das áreas de neurologia, pediatria, cardiologia e geriatria, totalizando uma média de 24 pacientes observados em cada uma das atividades práticas assistidas, que são divididas de I a VI.

Quanto aos recursos didáticos, materiais, equipamentos e corpo docente envolvidos no componente curricular avaliado, 57 entrevistados responderam que a estrutura fornecida foi suficiente e 34 entrevistados responderam que os equipamentos foram insuficientes e que faltaram recursos didáticos. Ressalta-se, porém que os recursos didáticos, materiais e equipamentos que compõe a Clínica de Fisioterapia da UNIUBE, são modernos, atualizados, em boas condições de uso e em número suficiente, assim como o corpo docente responsável pelo componente curricular avaliado neste estudo e responsável pela supervisão de estágio são no mínimo especialistas com experiência comprovada. Ressalta-se ainda que essas condições favoreçam a realidade com que os alunos irão se deparar no mercado de trabalho.

Em relação ao local onde a atividade pratica assistida foi realizada, 35 entrevistados afirmaram que o mesmo foi adequado, 3 entrevistados responderam que a Clínica Escola da UNIUBE e o Hospital Universitário influenciaram suas posturas profissionais após Atividade Prática Assistida. Constatou-se assim que o local influenciou positivamente no aprendizado desses alunos.

Ao serem questionados quanto às características mais marcantes de um professor para atuar na atividade prática assistida, 35 entrevistados responderam que a experiência profissional seria o quesito mais importante. Os estudos de Abreu e Masetto (1990) têm o sentido de mostrar que o professor atua como um facilitador da aprendizagem de seus 
alunos, tendo como papel principal, o de ajudar o aluno a aprender e criar condições para que ele adquira informações. Deve-se ressaltar diante disso que, uma das características marcantes do ensino está no processo de formação continuada do docente, que o leva a um processo de transformação, para se tornar um profissional preparado e satisfazer as necessidades dos alunos. A formação continuada por isso, deve ser estimulada pelas instituições de ensino.

Os alunos registraram que a integração do conteúdo teórico às atividades práticas foi o principal fator estimulante para a realização da atividade prática assistida. Em seguida apontaram a vontade de executar o conteúdo aprendido. A aprendizagem tornouse satisfatória a partir do momento em que o processo de ensino e aprendizagem se torna organizado e intencional (GUARIENTE, 1997).

Sobre os fatores que favoreceram o aprendizado na atividade prática assistida, os alunos responderam, em ordem de importância, que, em primeiro lugar veia à discussão dos casos clínicos com o professor supervisor, em segundo, a observação dos atendimentos, em terceiro a exposição do caso clínico pelo aluno estagiário, e em quarto, a realização dos relatórios. A partir dessa reflexão, dizemos que o professor atuou como um incentivador da prática clínica para que os objetivos das atividades práticas assistidas fossem alcançados. "As tarefas cognoscitivas (conteúdos, habilidades e desenvolvimento de capacidades intelectuais), expressas nos objetivos de ensino, precisam ser convertidas em objetivos do aluno" (LIBÂNEO, 1994, p.261).

Quanto aos fatores que prejudicaram o aprendizado, os alunos registraram como obstáculos, o desinteresse em primeiro lugar, vindo em seguida as faltas, ou seja, a falta de assiduidade, ainda, o não cumprimento da carga horária e a não realização dos relatórios. Para Carvalho et al. (1999), é fundamental a intervenção do professor, ao preparar o aluno para uma vivência satisfatória no campo da saúde.

Em relação ao papel do professor como facilitador do aprendizado os alunos caracterizaram por ordem de significância: a) o professor que cria condições para que o aluno adquira um senso crítico e seja mais reflexivo em suas atitudes, b) o professor que seja incentivador do aluno na busca e aperfeiçoamento do conhecimento científico, c) o que fornece o apoio que o aluno necessita para se sentir confiante e d) o que estimula o aluno no alcance dos seus objetivos. Freire (2003) torna claro alguns conceitos e idéias que merecem ser vivenciados e respeitados por todos os profissionais, que se dedicam a prática docente, tais como: ensinar não é transferir conhecimentos, mas criar as possibilidades para a sua produção ou construção; ensinar inexiste sem aprender; o 
educador precisa em sua prática docente, reforçar a capacidade crítica do educando, sua curiosidade, sua insubmissão; não há ensino sem pesquisa; ensinar exige risco, aceitação do novo e rejeição a qualquer forma de discriminação; ensinar exige curiosidade; ensinar exige disponibilidade para o diálogo.

Os entrevistados responderam que a atividade prática assistida foi importante para o desenvolvimento da segurança nos atendimentos aos pacientes do estágio curricular obrigatório. Isto demonstra com relevância, que a atuação da atividade prática assistida vem contribuindo para atuação do aluno com mais segurança nos estágios curriculares, principalmente para traçar os objetivos e as condutas dos atendimentos. Um estudo que analisou a eficácia do estágio supervisionado em fisioterapia na formação profissional do egresso por Gaiad e Sant'na (2005) demonstrou que o aluno está finalizando a graduação atualizado, porém sentindo a necessidade da experiência que os profissionais com mais tempo de carreira apresentam. Talvez se esses alunos tivessem a atividade prática assistida inserida dentro da grade curricular, ao ingressarem ao mercado de trabalho, teriam mais segurança e conseqüentemente mais experiência para lidar com as adversidades do caminho profissional.

Há trabalhos que evidenciaram a importância da pesquisa qualitativa, como essa realizada neste estudo. Para Martins e Bicudo (1989) a pesquisa qualitativa busca nas pessoas as experiências que vivem, portanto, dentro da dimensão subjetiva, a compreensão do ser, pois procura introduzir um rigor a fenômenos como angústia, ansiedade, medo, tristeza, alegria entre tantos outros, que não podem ser analisados quantitativamente por conterem dimensões pessoais e seriam melhores abordadas através da pesquisa qualitativa. Nas questões dissertativas podemos colher o real significado da existência do ser humano e captar o sentido ou o significado da vivência para a pessoa em determinadas situações por ela experimentadas no seu cotidiano. Ressalta-se que este estudo foi conduzido com pesquisa qualitativa, por isso, seus resultados têm grande valor para o objeto de estudo.

Por fim, os entrevistados referiram que o papel da atividade prática assistida, para a formação profissional, auxiliou no conhecimento do curso, proporcionou maior segurança para a aplicação do conhecimento adquirido, facilitando o elo entre a teoria e a prática, sendo estes considerados extremamente importantes para a formação profissional e ingresso no mercado de trabalho. 


\section{Conclusão}

Conclui-se que a implantação da atividade prática assistida, desde o início do curso de Fisioterapia foi importante para a atuação na prática clínica. A sua realização contribuiu para a segurança do aluno no estágio curricular.

Acreditou-se que há a necessidade de haver uma maior integração com as disciplinas alvo. A carga horária e o local foram considerados apropriados. Foram feitas sugestões para que se ampliassem as áreas de atuação. A estrutura de funcionamento quanto aos recursos didáticos, equipamentos e corpo docente foram considerados adequados para o aprendizado. Para atuar na atividade prática assistida, o professor deveria ter como característica marcante, ser experiente. O principal fator estimulante para a realização da atividade prática assistida vem sendo a integração do conteúdo teórico a prática. A discussão dos casos clínicos com o supervisor foi o principal fator que favoreceu o aprendizado na atividade prática assistida. O aluno desinteressado foi o fator que mais prejudicou o aprendizado. O professor que criou condições para que o aluno adquirisse um senso crítico e reflexivo em suas atitudes foi considerado o principal papel do professor como facilitador do aprendizado dos alunos.

Sugeriu-se que fosse implantada a disciplina de atividade prática assistida nos cursos de Fisioterapia a fim de atingir as diretrizes curriculares propostas pelo MEC em 2002.

\section{Referências}

ABREU, M. C.; MASETTO, M. T. O professor em aula: prática e princípios teóricos. 8. ed. São Paulo: MG Editores Associados, 1990.

BAFFI, M. A. T. Projeto político pedagógico: um estudo introdutório. In: BELLO, J. L. de P. Pedagogia em foco. Rio de Janeiro, 2002. Disponível em:

<http://www.pedagogiaemfoco.pro.br/gppp03.htm>. Acesso em 28 jan. 2008.

BRASIL. Ministério da Educação. Resolução CNE/CES no. 4, 192/2002. Institui diretrizes curriculares nacionais do curso de graduação em Fisioterapia. Brasília, Conselho Nacional de Educação, 2002. 
Ministério da Educação. Cadastro das Instituições de Educação Superior. Disponível em: http://www.educacaosuperior.inep.gov.br/funcional/lista_cursos.asp Acesso em: 1 set. 2008.

CARVALHO, M. D. B.; PELLOSO, S. M.; VALSECCHI, E. A. S. S. et al. Expectativas dos alunos de enfermagem frente ao primeiro estágio em hospital. Rev. Esc. Enf. USP, v.33, n. 2, p. 200-6, jun.1999.

FREIDLANDER, M. R. Vantagens do ensino laboratório de enfermagem. Rev. Esc. Enf. USP. V.28, n.2, p.227-233, ago. 1994.

FREIRE, P. Pedagogia da autonomia: saberes necessários à prática educativa. 26. ed. São Paulo: Paz e Terra, 2003.

GAIAD, T. P.; SANT'ANA, D. M. G. Análise da Eficácia do Estágio Supervisionado em Fisioterapia na Formação Profissional: Uma Visão do Egresso. Arq. Ciênc. Saúde Unipar, Umuarama, v.9 (2), mai./ago. p. 65-70, 2005.

GUARIENTE, M. H. D. M. Aspectos Pedagógicos no ensino de Fundamentos de Enfermagem: uma construção participativa. Londrina, 1997. Dissertação (Mestrado). Universidade Estadual de Londrina.

KULCSAR, R. O Estágio Supervisionado Como Atividade Integradora. In: FAZENDA, I. C. A. et al. A Prática de Ensino e o Estágio supervisionado. 7. ed. Campinas: Papirus, $2001.70 \mathrm{p}$.

LIBÂNEO, J. C. Didática. São Paulo: Cortez, 1994.

MATHEUS, M. C. C. et al. O uso do diário de campo de estágio favorece o autoconhecimento da aluna e o movimento aluna-professora. Acta Paul. Enf. V.9, n.3, set./dez. 1996.

MARTINS, M.; BICUDO, M. A. V. Estudo sobre existencialismo, fenomenologia e educação. São Paulo: Morais, 1989.

MINAYO, M. C. de S. O desafio do conhecimento: pesquisa qualitativa em saúde. 2. ed. São Paulo: Hucitec, 1993.

RODRIGUES, E. N. Primeiro estágio curricular: relato de experiência. Rev. Bras.

Enferm. Brasília, v.48, n.4, p. 436-443, out./dez.1995.

UNIUBE. Universidade de Uberaba. Plano de Ensino da Atividade Prática Assistida, 2003. Uberaba, Minas Gerais, 2002.

Minas Gerais, 2002.

Projeto pedagógico do curso de graduação em Fisioterapia, 2003. Uberaba,

Recebido para publicação em: 19/10/2008

Aceito: 20/12/2008 